\title{
DIAPHRAGM AXIAL CAPACITY FOR EXTERNAL DIAPHRAGM CONNECTIONS (EDCS) IN SQUARE CFST COLUMN STRUCTURES
}

\author{
Helmy Tjahjanto ${ }^{1}$, Gregory MacRae ${ }^{2}$, Anthony Abu ${ }^{3}$, \\ Charles Clifton $^{4}$, Tessa Beetham ${ }^{5}$ and Nandor Mago ${ }^{6}$
}

\author{
(Submitted February 2019; Reviewed May 2019; Accepted June 2019)
}

\begin{abstract}
This paper evaluates external diaphragm axial capacity in moment frame structures with square concretefilled steel tubular (CFST) columns considering bidirectional loading. Three design methods were considered: (1) the CIDECT method; (2) the equivalent beam method; and (3) the tie method. Finite element analyses were conducted to investigate the behaviour of an external diaphragm plate connected to a square CFST column under varied bidirectional diaphragm axial forces. It is shown that the perpendicular diaphragm axial forces did not reduce the diaphragm axial capacity significantly, which is consistent with the assumptions made by the CIDECT method and the tie method. The CIDECT method, in some cases, was not conservative. Among the considered methods, the tie method was the most justifiable method, although in some cases the capacity predictions were too conservative. The tie method was later modified by considering the contribution of the steel tube in addition to the diaphragm plate in calculating the diaphragm axial capacity. The modified tie method was shown to accurately predict a lower bound estimate of the capacity of an external diaphragm connection.
\end{abstract}

\section{INTRODUCTION}

Concrete-filled steel tubular (CFST) columns have been widely used because of their excellent performance in earthquake resisting frame structures. The interaction between the concrete core and the steel tube improves the strength and the ductility of the column. In some cases, moment-resisting frame structures with CFST columns can be more economical than the structures with $\mathrm{H}$-shaped steel columns. The steel consumption of a structure with CFST columns can be reduced by $10 \%$ as concluded from trial design cases conducted by Morino et al. [1]. The construction efficiency can also be increased by minimizing the needs of labour and formwork materials [2].

Most CFST columns have circular or square shapes, which are suitable for two-way moment-resisting frame structures because they have equal strength and stiffness in the main orthogonal directions. Although the circular-shaped CFST columns have higher axial capacity, the square-shaped CFST columns are more preferable because they have flat surfaces, which make them more suitable for making connections.

Various types of steel-beam-to-CFST-column connections have been proposed and investigated. Alostaz \& Schneider [3] and Schneider \& Alostaz [4] tested several connection types for circular CFST columns, including: a simple welded connection; connections with additional connectors (continuous web plates, diaphragm plates, embedded deformed bars, interior headed studs, or headed studs on web plates); and connections with continuous beam flanges or continuous beams. It was found that the continuous beam connection had the highest strength and ductility. Some other connection types have also been studied, these include: beam end-plate connections with through-bolts
$[5,6,7]$; beam end-plate connections and T-stub connections with anchored or blind bolts $[8,9]$; welded T-stiffeners [10, 11, 12]; and welded diaphragm plate connections [13, 14, 15]

Each connection type has advantages and disadvantages as summarized by Chunhaviriyakul et al. [16]. Among the considered connection types, the diaphragm-type connections have some important characteristics, such as: their efficient force transfer mechanisms; their suitability for two-way frames; and their applicability for low damage connections. The diaphragm-type connections can be made with throughdiaphragms, internal diaphragms, or external diaphragms. The connections with external diaphragm plates (Fig. 1) require simpler welding methods and also avoid concrete compacting issues which often exist in the through-diaphragm or internal diaphragm connections. Voids resulted from poor concrete compaction decrease the strength of the composite column.

Although the external diaphragm connections (EDCs) have some advantages to be used in moment-resisting frames with CFST columns, a limited number of studies had been conducted, especially those considering the effect of bidirectional diaphragm axial loading. It is also necessary to have a simple and robust design method for EDCs under bidirectional diaphragm axial loading. In order to address this need, answers are sought to the following questions:

1) What design methods have been proposed for external diaphragm connections?

2) Which design method shows the best agreement with the numerical analysis results?

3) What modification can be made to improve the accuracy of the design method?

\footnotetext{
1 Corresponding Author, Parahyangan Catholic University, Bandung, Indonesia, helmy.hermawan@unpar.ac.id

${ }^{2}$ Associate Professor, University of Canterbury, Christchurch, New Zealand (Member)

${ }^{3}$ Senior Lecturer, University of Canterbury, Christchurch, New Zealand

${ }^{4}$ Associate Professor, University of Auckland, Auckland, New Zealand (Member)

5 Senior Structural Engineer, Aurecon, Christchurch, New Zealand

${ }^{6}$ Finite Element Analyst, Heavy Engineering Research Association (HERA), Manukau,, New Zealand
} 


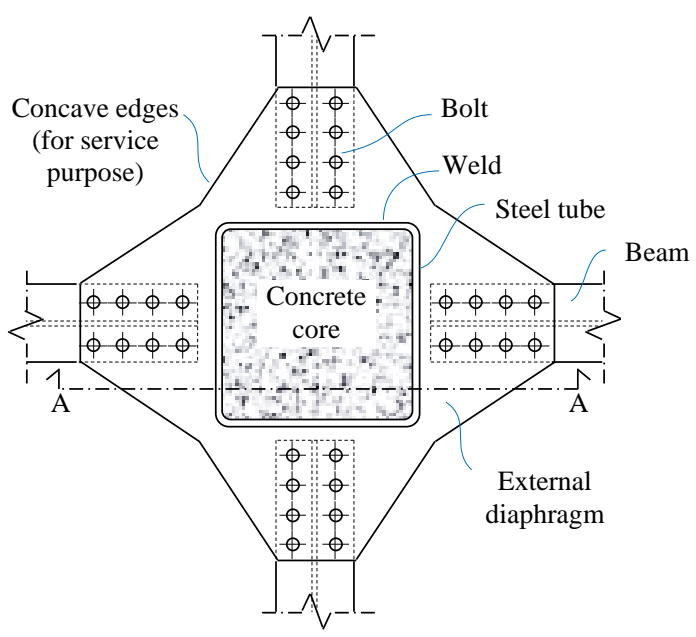

(a) Top view

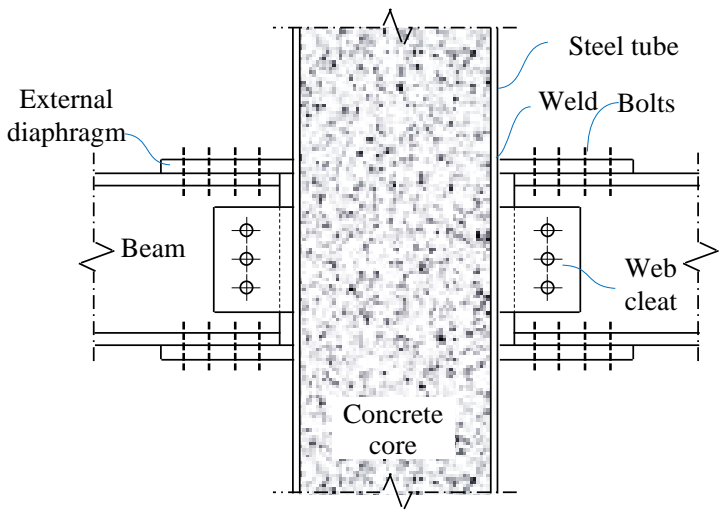

(b) Section A

Figure 1: A square CFST column connection with external diaphragm connection.

\section{CONSIDERED DESIGN METHODS}

In moment-resisting frame structures with CFST columns, external diaphragms are designed to resist tension and compression forces resulting from the beam end moments as shown in Fig. 2. The tension forces are more critical because the steel tube has to resist the out-of-plane deformation alone. In the compression side, the forces are transferred to the concrete core through bearing actions. Accordingly, the following design methods only consider the external diaphragm tension capacity.

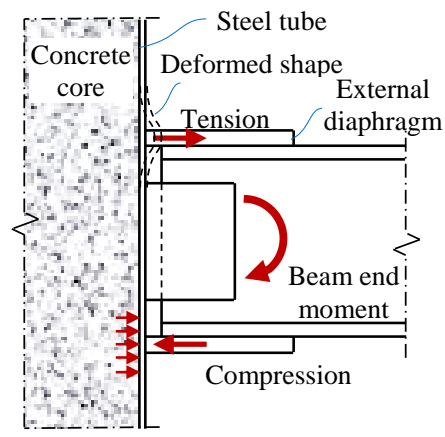

Figure 2: Force transfer mechanism in an external diaphragm connection.

\section{The CIDECT Method}

The CIDECT (Comité International pour le Développement et l'Etude de la Construction Tubulaire) method was described in Kurobane et al. [17]. It was developed based on studies conducted in Japan. It has two direct design equations for predicting the ultimate strength of square or rectangular CFST column connections with external diaphragms. The formulation in Eq. (1) was derived from the ultimate strength formula for plain steel column connections with a greater resistance factor considering the concrete core restraining effects. The formulation in Eq. (2) was derived from the yield strength equation for circular hollow section (CHS) column connections. A factor equal to $1.0 / 0.7$ was used to convert the yield strength equation to the ultimate resistance equation according to structural steel connections design recommendations in Japan.

The dimensional parameters and the range of validity of the method are described in Fig. 3. If the diaphragm side angle, $\theta \leq$ $30^{\circ}$, the connections are categorized as Type I, and if $30^{\circ} \leq \theta \leq$ $45^{\circ}$, the connections are categorized as Type II. For Type I, the diaphragm tension capacity, $T_{\text {diaph }}$, can be taken as the larger value from Eq. (1) and Eq. (2). For Type II, $T_{\text {diaph }}$, is calculated using Eq. (2) alone. In those equations, $t_{t}$ and $t_{d}$ are the thicknesses of the column tube and the diaphragm plate respectively, $b_{c}$ is the column width, $h_{d}$ is the projected width of the diaphragm at the critical section, $f_{y t}$ and $f_{y d}$ are the yield strengths of the column tube and diaphragm plate respectively, and $f_{u d}$ is the ultimate tensile strength of the diaphragm plate.

$T_{\text {diaph }}=3.74\left(\frac{t_{t}}{b_{c}}\right)^{\frac{2}{3}}\left(\frac{t_{d}}{b_{c}}\right)^{\frac{2}{3}}\left(\frac{t_{t}+h_{d}}{b_{c}}\right)^{\frac{1}{3}} b_{c} f_{u d}$

$T_{\text {diaph }}=2.86\left(4 t_{t}+t_{d}\right) t_{t} f_{y t}+3.30 h_{d} t_{d} f_{y d}$

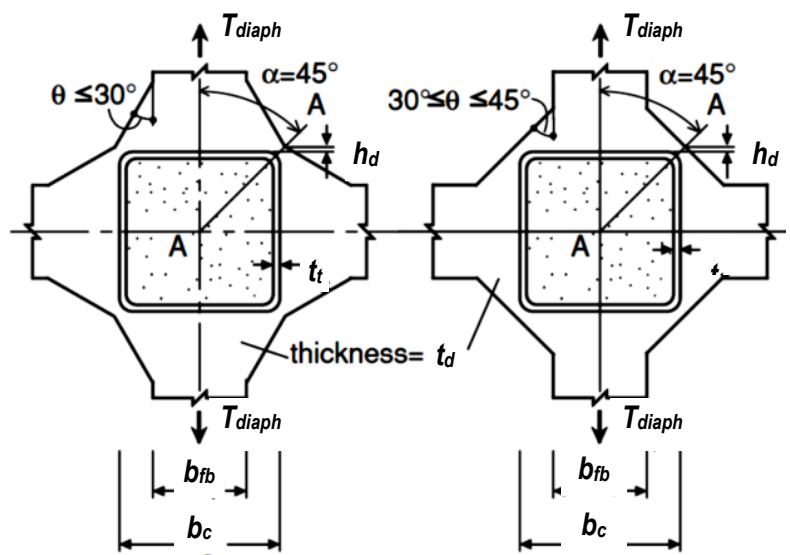

\begin{tabular}{ll} 
Range of validity & \\
\hline Type I: & Type II: \\
$20 \leq b_{c} / t_{t} \leq 50$ & $h_{d} / b_{c} \geq 0.1 t_{f b} / t_{d}$ \\
$0.75 \leq t_{d} / t_{t} \leq 2$ & \\
$t_{d} \geq t_{f b}$ & \\
$h_{d} / b_{c} \geq 0.1 t_{f b} / t_{d}$ &
\end{tabular}

Figure 3: Dimensional parameters for the CIDECT method.

\section{The Equivalent Beam Method}

The equivalent beam method was proposed by MacRae [18]. In this method, external diaphragm plates and column tubes are assumed to form T-sectioned beams, as shown in Fig. 4. The Tsectioned beams may simply and conservatively be assumed to be fixed at the end of compression sides, as shown in Fig. 5. Consequently, the equivalent frame configurations are different for one-way and two-way loadings. The equivalent beams are elastically designed to resist the critical bending moment, shear force, and axial force resulting from the diaphragm tension forces. 


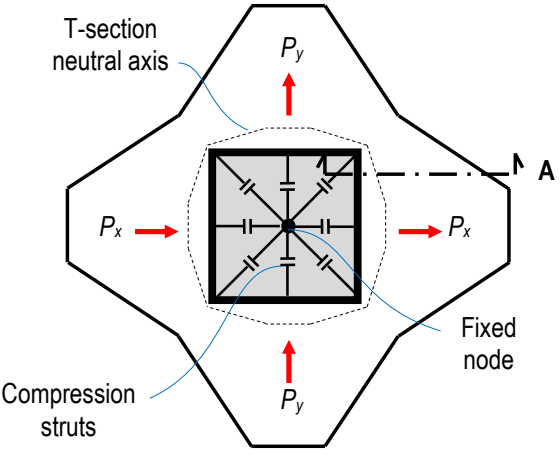

(a) External diaphragm plan

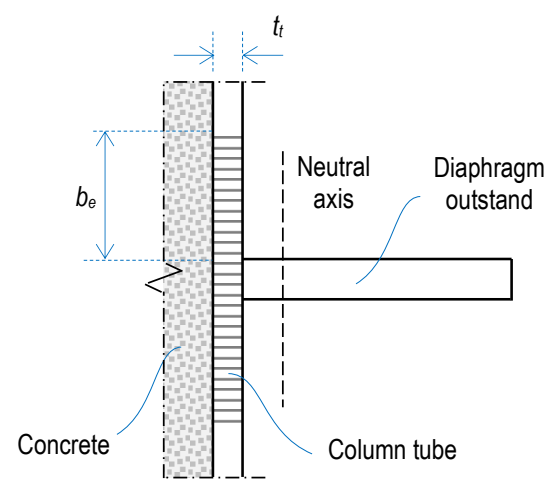

(b) Detail of the T-section (Section A)

Figure 4: Equivalent beam analogy.

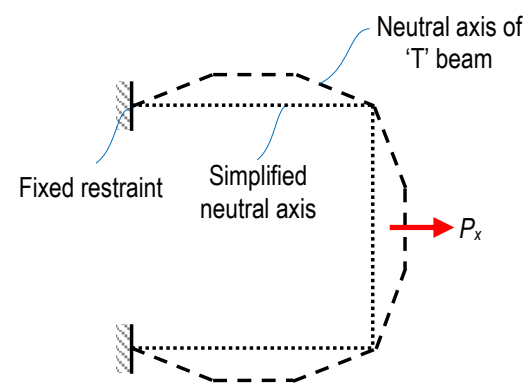

(a) One-way loading

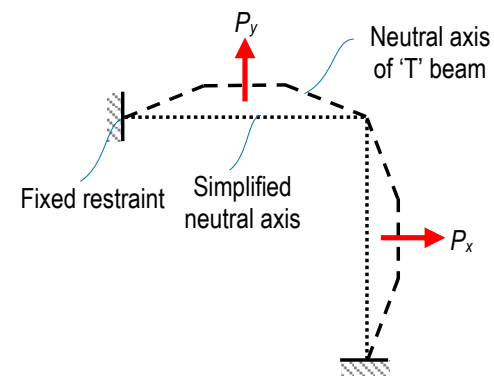

(b) Two-way loading

Figure 5: Simplified model for the equivalent beam method (plan view).

\section{The Tie Method}

The tie method was initially proposed by Beetham. The method was developed assuming tensile stress bands on the diaphragm plates when critical diaphragm axial forces, $P_{x}$ and $P_{y}$, occur, as shown in Fig. 6(a). By ignoring the compression forces, the diaphragm plate is considered to behave in a similar way if a tie (or a string) is looped around the column and pulled out at one or two sides as shown in Fig. 6(b). In this approach, there is no interaction between two perpendicular diaphragm axial forces, $P_{x}$ and $P_{y}$, so that each side of the diaphragm can be designed separately. The diaphragm design capacity is defined as the diaphragm axial force, $P_{x}$ or $P_{y}$, that causes the tie element to reach its tension capacity at the critical section. The tension capacity can be defined as the yielding of the diaphragm plate critical section in tension.

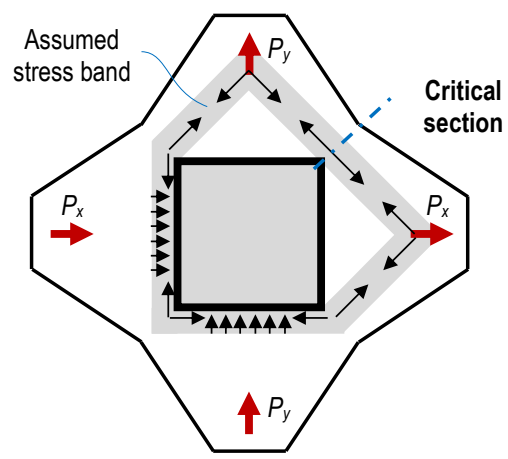

(a) Assumed stress band

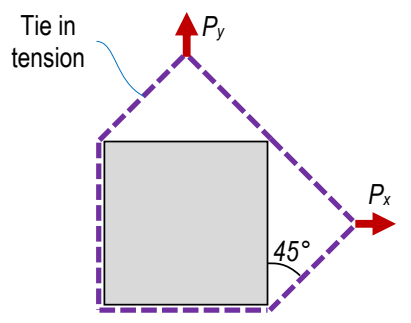

(b) Tie element approach

Figure 6: The tie method concept and simplification.

\section{FINITE ELEMENT ANALYSIS}

Finite element analyses (FEA) are conducted using ABAQUS [19] to investigate the behaviour of external diaphragms connected to CFST columns under in-plane axial loading. Each model consists of one CFST column and one diaphragm plate connected to the column tube. Homogenous shell elements are used to model the diaphragm plates and the steel tube. Bilinear stress-strain relationship, with modulus of elasticity of 200000 MPa and varied yield strengths, is used to model the steel material behaviour. The concrete core is modelled as a rigid solid element, assuming that the strength of the steel tube and diaphragm plate determine the connection capacity as defined in the considered methods. The interaction between the concrete core and the steel tube internal surfaces is defined as a normal "hard" contact behavior. This feature allows separation between the contacted surfaces under tension, and results in contact pressure under compression. Friction between the two surfaces is ignored. The weld between the diaphragm plate and tube is assumed to develop full strength and modeled by merging the plates into one instance.

A profile of the modelled connection detail is given in Fig. 7. For parametric evaluations, parameters $t_{t}, h_{d}, t_{d}$, and $f_{y d}$, are varied, as described in Table 1. Fixed parameters are: column width and length ( $b_{c}=600 \mathrm{~mm}$ and $\left.L_{c m}=1200 \mathrm{~mm}\right)$; diaphragm edge length and width $\left(L_{d}=525 \mathrm{~mm}\right.$ and $\left.b_{d}=230 \mathrm{~mm}\right)$; and steel tube yield strength $\left(f_{y t}=300 \mathrm{MPa}\right)$. The outer corner radius, $r_{c}$, is taken as three times as wide as the column tube thickness, $t_{t}$, as specified for standard cold-formed square hollow sections with the thickness equal to $3 \mathrm{~mm}$ or larger [20]. Fixed restraints are applied at the top and bottom ends of the 
steel tube, as shown in Fig. 8. The diaphragm forces are applied as nodal shear forces at the bolt centres on each side of the diaphragm and gradually increased. Diaphragm forces at the tension and compression sides of the column are applied simultaneously both for the one-direction ( $\mathrm{x}$-axis direction only) and the two-direction (x-axis and $\mathrm{y}$-axis) loading cases.

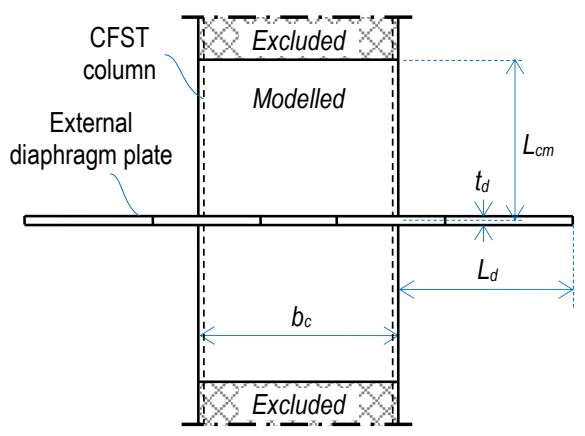

(a) Side view

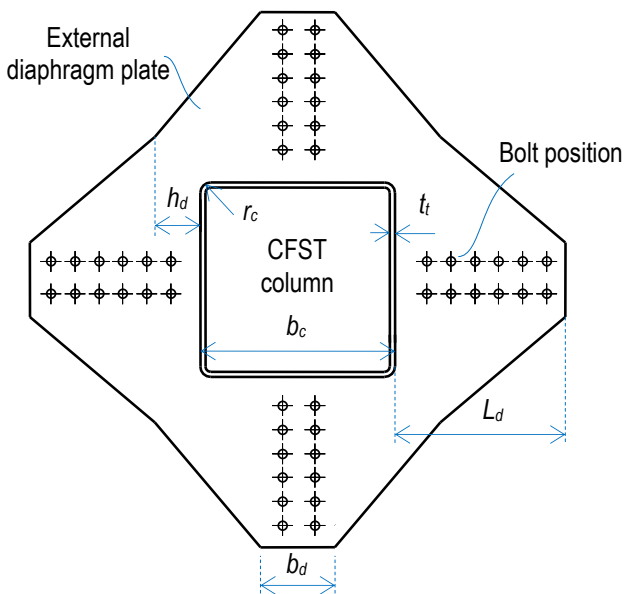

(b) Plan view

Figure 7: Modelled profile.

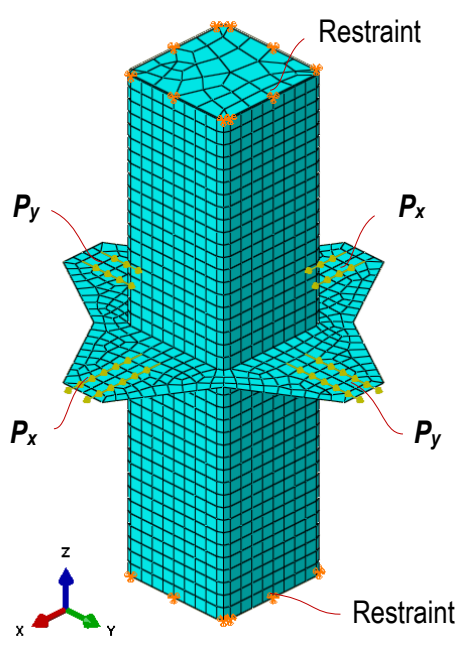

Figure 8: External diaphragm connection numerical model (isometric view).
Table 1: Numerical model parameters.

\begin{tabular}{llll}
\hline \multicolumn{4}{c}{ Varied parameters } \\
\hline$t_{t}$ & $h_{d}$ & $t_{d}$ & $f_{\text {yd }}$ \\
$(\mathrm{mm})$ & $(\mathrm{mm})$ & $(\mathrm{mm})$ & $(\mathrm{MPa})$ \\
\hline 12 & 20 & 15 & 250 \\
16 & 80 & 20 & 300 \\
20 & 140 & 25 & 350 \\
\hline
\end{tabular}

The applied diaphragm forces should be limited to avoid a large residual deformation of the column tube. For this reason, the diaphragm design capacity is defined as the force which results in a residual displacement, $\delta_{\text {res }}$, at the midpoint of the column tube equals to $0.083 \%(<0.1 \%)$ of the column dimension, as illustrated in Fig. 9. For the $600 \mathrm{~mm}$ width column, this is 0.5 $\mathrm{mm}$. Such an approach is similar to the $0.2 \%$ offset strain used to obtain yield strength in metals.
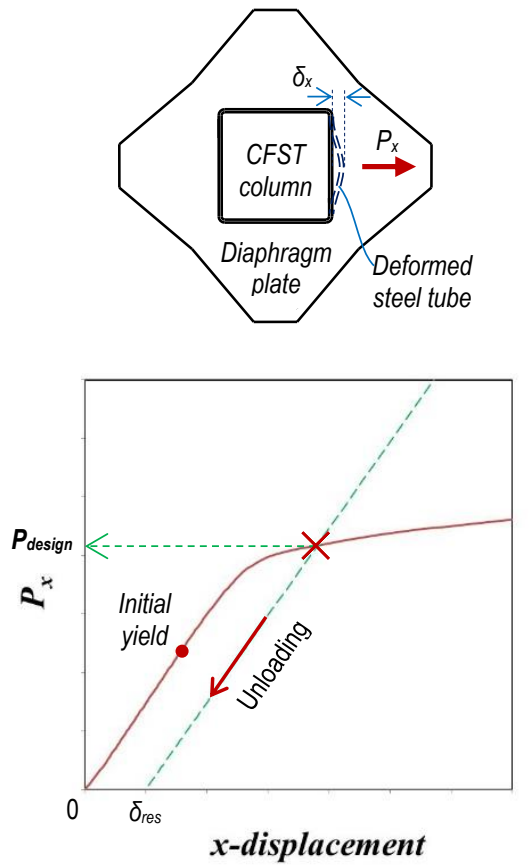

Figure 9: Diaphragm axial capacity determination.

\section{EVALUATION OF THE DESIGN METHODS}

The diaphragm axial capacity is evaluated using the considered design methods and finite element analysis for three configurations: (1) Minimum ( $t_{t}=12 \mathrm{~mm}, h_{d}=20 \mathrm{~mm}, t_{d}=15$ $\mathrm{mm})$; (2) Medium ( $\left.t_{t}=16 \mathrm{~mm}, h_{d}=80 \mathrm{~mm}, t_{d}=20 \mathrm{~mm}\right)$; and (3) Maximum ( $\left.t_{t}=20 \mathrm{~mm}, h_{d}=140 \mathrm{~mm}, t_{d}=25 \mathrm{~mm}\right)$. The other dimensions are fixed: $b_{c}=600 \mathrm{~mm} ; L_{d}=525 \mathrm{~mm} ; b_{d}=230 \mathrm{~mm}$, and $t_{f b}=17.3 \mathrm{~mm}$ (assuming the 610UB113 section is used for the connected beams). The steel material properties are: $f_{y d}=f_{y t}$ $=300 \mathrm{MPa}$ and $f_{u d}=430 \mathrm{MPa}$

The following design examples describe the axial capacity calculation of an external diaphragm connection with the medium configuration, which has the following dimensions: $t_{t}$ $=16 \mathrm{~mm}, h_{d}=80 \mathrm{~mm}$ and $t_{d}=20 \mathrm{~mm}$.

\section{The CIDECT Method}

The angle of external diaphragm side:

$\theta=\tan ^{-1}\left(\frac{\frac{\mathrm{b}_{\mathrm{c}}}{2}+\mathrm{h}_{\mathrm{d}}-\frac{\mathrm{b}_{\mathrm{d}}}{2}}{\mathrm{~L}_{\mathrm{d}}-\mathrm{h}_{\mathrm{d}}}\right)=\tan ^{-1}\left(\frac{\frac{600 \mathrm{~mm}}{2}+80 \mathrm{~mm}-\frac{230 \mathrm{~mm}}{2}}{525 \mathrm{~mm}-80 \mathrm{~mm}}\right)=30.774^{\circ}>30^{\circ}$

The diaphragm connection is categorized as Type II. Hence, the diaphragm tension capacity, $T_{\text {diaph }}$, is calculated using Eq. (2). 
$T_{\text {diaph }}=2737.15 \mathrm{kN}$

The diaphragm tension capacity, $T_{\text {diaph }}$, applies for both oneway and two-way loading.

\section{The Equivalent Beam Method}

The effective width of column tube, as the flange of the Tsection, is determined using the yield slenderness limit for onesided supported flat plate elements under uniform compression (NZS3404: Part 1, Table 5.2 [21]):

$b_{\text {eff }}=16 t_{t} \sqrt{\frac{250 \mathrm{MPa}}{f_{y t}}}=233.695 \mathrm{~mm}$

Total width of the flange is:

$b_{f}=2 b_{\text {eff }}+t_{d}=487.39 \mathrm{~mm}$

The effective width of the diaphragm plate, as the stem of the $\mathrm{T}$-section, is determined using the yield slenderness limit for one-sided supported flat plate elements under non-uniform compression (NZS 3404: Part 1 1997):

$h_{\text {eff }}=25 t_{d} \sqrt{\frac{250 \mathrm{MPa}}{f_{y d}}}=456.44 \mathrm{~mm}>h_{d}=80 \mathrm{~mm}$

$h_{\text {stem }}=h_{d}=80 \mathrm{~mm}$

The section properties (about neutral axis) of the T-section are:

$A_{g}=9398.24 \mathrm{~mm}^{2}$

$I=3.571 \times 10^{6} \mathrm{~mm}^{4}$

$S_{\text {min }}=4.473 \times 10^{4} \mathrm{~mm}^{3}$

Flexural, axial and shear capacities of the section are:

$M_{n}=S_{\min } f_{y}=13.42 \mathrm{kN} . \mathrm{m}$

$T_{n}=A_{g} f_{y}=2819 \mathrm{kN}$

$V_{n}=h_{\text {stem }} t_{d}\left(0.6 f_{y}\right)=288 \mathrm{kN}$

Maximum forces at critical locations due to concentrated forces, $P$, on frame with length, $L$, are:

For one-way loading: (see Fig 5(a))

$M_{\max }=\frac{P L}{2} ; N_{\max }=\frac{P}{2} ; Q_{\max }=\frac{P}{2}$

For two-way loading: (see Fig 5 (b))

$M_{\max }=\frac{P L}{8} ; N_{\max }=\frac{P}{2} ; Q_{\max }=\frac{P}{2}$

Where $L$ is simply taken as the column width, $b_{c}=600 \mathrm{~mm}$.

The loads that cause yielding on the T-section beam are:

For one-way loading:

$T_{\text {diaph }}=\min \left[\left(\frac{12 M_{n}}{L}\right),\left(2 T_{n}\right),\left(2 T_{n}\right)\right]$

$T_{\text {diaph }}=268.4 \mathrm{kN}$

For two-way loading:

$T_{\text {diaph }}=\min \left[\left(\frac{8 M_{n}}{L}\right),\left(2 T_{n}\right),\left(2 T_{n}\right)\right]$

$T_{\text {diaph }}=178.9 \mathrm{kN}$

\section{The Tie Method}

In the tie method, $T_{\text {diaph }}$ values are obtained conservatively by calculating only the tension strength of the diaphragm plate at the critical section.

The tie section area at critical section using full width of $h_{d}$ :
$A_{c r}=t_{d} h_{d} \sqrt{2}=2262.7 \mathrm{~mm}^{2}$

External diaphragm tension capacity:

$\boldsymbol{T}_{\text {diaph }}=A_{c r} f_{y d} \sqrt{2}=960 \mathbf{k N}$

The diaphragm tension capacity, $T_{\text {diaph }}$, applies for both oneway and two-way loading.

\section{Comparison with FE Results}

The values of external diaphragm design capacity, $T_{\text {diaph }}$, based on three numerical results for the minimum, medium, and maximum configurations are compared with the ones determined from the FEA, as shown in Table 2. No design capacity is obtained using the CIDECT method for the minimum configuration because it is out of the range of validity. For the other configurations, the CIDECT method results in non-conservative design capacity values. The equivalent beam method and the tie method always result in much lower values than those determined from the FEA.

Table 2: Design capacities of external diaphragm connections.

\begin{tabular}{|c|c|c|c|c|c|}
\hline \multirow[t]{2}{*}{ Configuration } & \multirow[t]{2}{*}{ Case } & \multirow[t]{2}{*}{$\begin{array}{c}T_{\text {diaph }} \text { from } \\
\text { FEA }\end{array}$} & \multicolumn{3}{|c|}{$\begin{array}{c}T_{\text {diaph }} \\
\text { (ratio to FEA in \%) }\end{array}$} \\
\hline & & & CIDECT & $\begin{array}{c}\text { Equivalent } \\
\text { beam }\end{array}$ & Tie \\
\hline \multirow{2}{*}{$\begin{array}{c}\underline{\text { Minimum }} \\
t_{t}=12 \mathrm{~mm} \\
h_{d}=20 \mathrm{~mm} \\
t_{d}=15 \mathrm{~mm}\end{array}$} & $P_{y}=0$ & $832 \mathrm{kN}$ & $O R$ & $\begin{array}{l}29 \mathrm{kN} \\
(4 \%)\end{array}$ & $\begin{array}{l}180 \mathrm{kN} \\
(22 \%)\end{array}$ \\
\hline & $P_{y}=P_{x}$ & $833 \mathrm{kN}$ & $O R$ & $\begin{array}{l}19 \mathrm{kN} \\
(2 \%)\end{array}$ & $\begin{array}{l}180 \mathrm{kN} \\
(22 \%)\end{array}$ \\
\hline \multirow{2}{*}{$\begin{array}{c}\underline{\text { Medium }} \\
t_{t}=16 \mathrm{~mm} \\
h_{d}=80 \mathrm{~mm} \\
t_{d}=20 \mathrm{~mm}\end{array}$} & $P_{y}=0$ & $2056 \mathrm{kN}$ & $\begin{array}{r}2737 \mathrm{kN} \\
(133 \%)\end{array}$ & $\begin{array}{r}268 \mathrm{kN} \\
(13 \%)\end{array}$ & $\begin{array}{l}960 \mathrm{kN} \\
(47 \%)\end{array}$ \\
\hline & $P_{y}=P_{x}$ & $2058 \mathrm{kN}$ & $\begin{array}{r}2737 \mathrm{kN} \\
(133 \%)\end{array}$ & $\begin{array}{c}179 \mathrm{kN} \\
(9 \%)\end{array}$ & $\begin{array}{l}960 \mathrm{kN} \\
(47 \%)\end{array}$ \\
\hline \multirow{2}{*}{$\begin{aligned} \text { Maximum } \\
t_{t}=20 \mathrm{~mm} \\
h_{d}=140 \mathrm{~mm} \\
t_{d}=25 \mathrm{~mm}\end{aligned}$} & $P_{y}=0$ & $3426 \mathrm{kN}$ & $\begin{array}{l}5267 \mathrm{kN} \\
(154 \%)\end{array}$ & $\begin{array}{l}945 \mathrm{kN} \\
(28 \%)\end{array}$ & $\begin{array}{c}2100 \mathrm{kN} \\
(61 \%)\end{array}$ \\
\hline & $P_{y}=P_{x}$ & $3186 \mathrm{kN}$ & $\begin{array}{l}5267 \mathrm{kN} \\
(165 \%)\end{array}$ & $\begin{array}{l}630 \mathrm{kN} \\
(20 \%)\end{array}$ & $\begin{array}{c}2100 \mathrm{kN} \\
(66 \%)\end{array}$ \\
\hline
\end{tabular}

OR: out of the range of validity

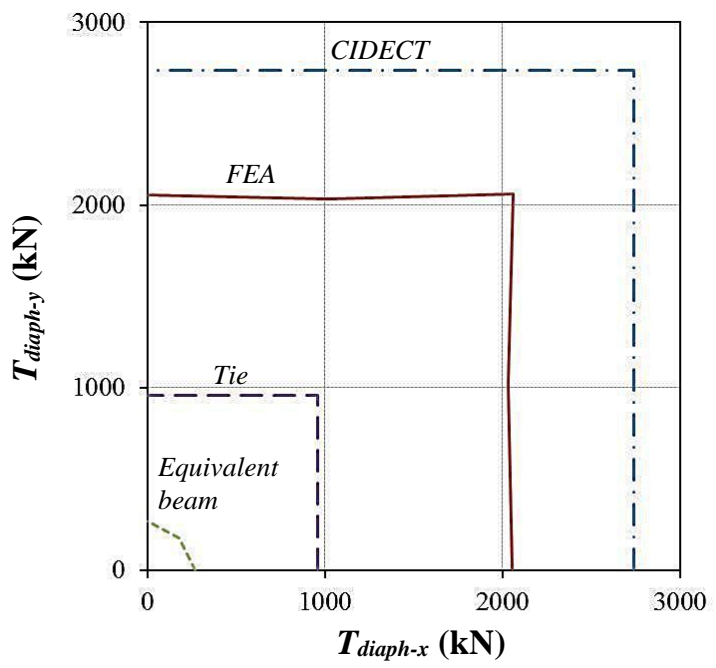

Figure 10: Bidirectional interaction of external diaphragm axial capacity (medium configuration).

Both the CIDECT method and the tie method assume that the diaphragm axial capacity is not affected by the application of perpendicular forces, while in the equivalent beam method the diaphragm axial capacities are affected by the perpendicular 
axial forces (Table 2). For the medium and maximum configurations, the perpendicular axial forces reduce by $33 \%$ of the capacity for one-way loading, if calculated using the equivalent beam method. From the FEA results, it is shown that the diaphragm design capacities are not significantly affected by the perpendicular forces, which conform to the assumption of the CIDECT method and the tie method. The design capacity interactions for the medium configuration are shown in Fig. 10.

\section{MODIFICATION OF THE TIE METHOD}

Among the considered methods, the tie method is the most suitable design method due to its consistency with the finite element results that the diaphragm axial capacity is not affected by the perpendicular loading. However, the capacity predicted using the tie method is too conservative. The accuracy of the tie method can be improved by including the steel tube contribution in the effective tie area calculation at the critical section (Fig. 11). The critical tie element section consists of a diaphragm plate and a column steel tube which form a T-shaped section, as shown in Fig. 11(b). The diaphragm axial capacity, $T_{\text {diaph }}$, can be calculated using Eq. (3). The width factors, $\alpha_{t}$ and $\alpha_{d}$, are introduced to determine the portions of the column steel tube and the diaphragm plate which contribute to the tie strength

$$
T_{\text {diaph }}=\left(\alpha_{t} b_{c} t_{t} f_{y t}+\alpha_{d} h_{d} \sqrt{2} t_{d} f_{y d}\right) \sqrt{2}
$$

Where: $f_{y t}=$ the tube yield strength; $f_{y d}=$ the diaphragm yield strength; $t_{t}=$ the steel tube thickness; $t_{d}=$ the diaphragm thickness; $b_{c}=$ the column width; $h_{d}=$ the diaphragm critical width; $\alpha_{t}=$ the tube width factor; and $\alpha_{d}=$ the diaphragm width factor.

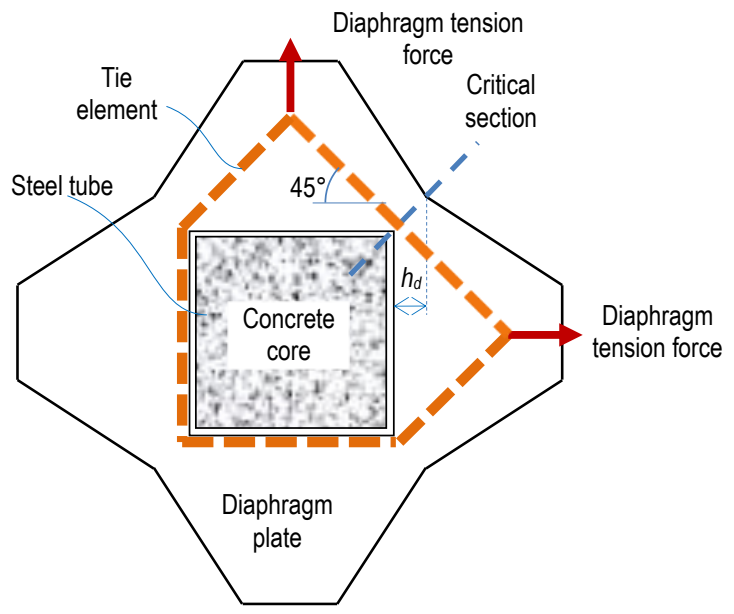

(a) Tie element model

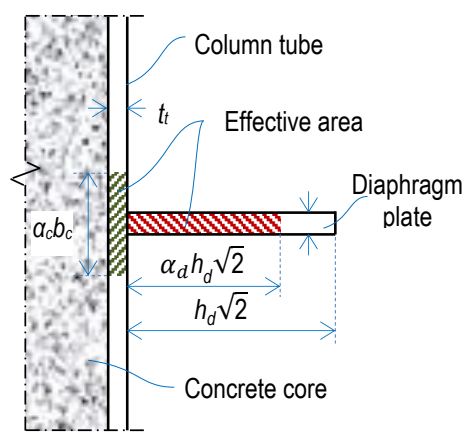

(b) Effective area at the critical

Figure 11: The tie element model and critical section area.

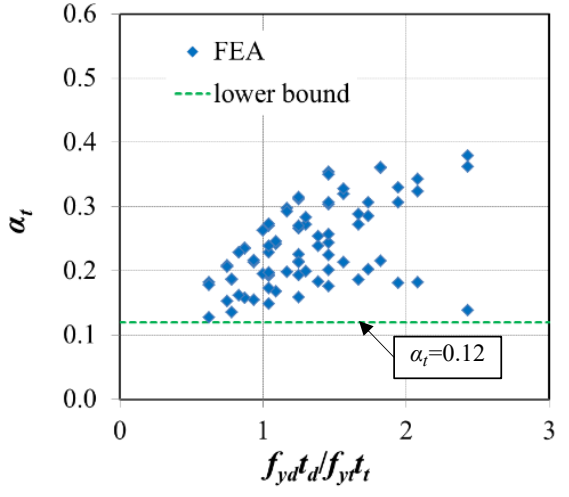

(a) $\alpha_{d}=1.0$

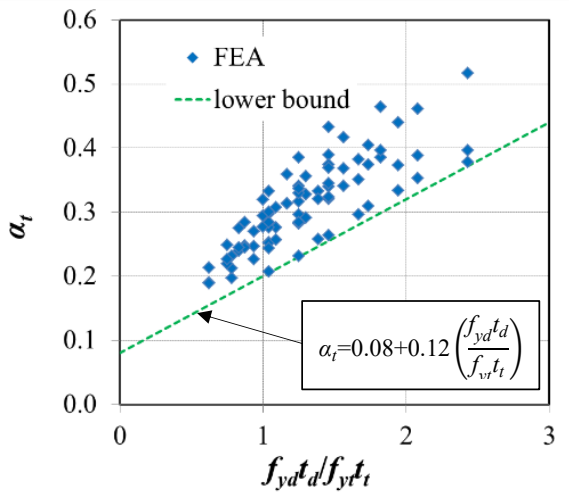

(b) $\alpha_{d}=0.7$

Figure 12: The column tube width factor, at, versus a nondimensional parameter, $\frac{f_{y d} t_{d}}{f_{y t} t_{t}}$.

A number of diaphragm axial capacity values, $T_{\text {diaph }}$, are obtained from FEA for all modeled configurations. By assuming $\alpha_{d}$ as a constant value, the corresponding $\alpha_{t}$ values for corresponding $T_{\text {diaph }}$ values versus a non-dimensional parameter, $f_{y d} t_{d} / f_{y t} t_{t}$ are plotted in Fig. 12. The first approach assumes that the entire section of the diaphragm plate width reaches its yield stress $\left(\alpha_{d}=1.0\right)$ and the $\alpha_{c}$ values are plotted as shown in Fig. 12(a). From this approach, the lower bound value for $\alpha_{d}$ can be taken as 0.12 . The second approach assumes only some part of the diaphragm width reaches its yield stress $\left(\alpha_{d}=0.7\right)$ as shown in Fig. 12(b). The value of $\alpha_{t}$ tends to increase linearly as the $f_{y d} t_{d} d f_{y t} t_{t}$ increases. The lower bound value for $\alpha_{t}$ can be determined as a linear equation, as follows:

$\alpha_{t}=0.08+0.12\left(\frac{f_{y d} t_{d}}{f_{y t} t_{t}}\right)$

It can be seen that the second approach gives more accurate results than the first one in predicting the diaphragm capacity. Therefore, the design procedure using the modified tie method, for the similar diaphragm configurations, can be summarized as follows:

1) Identify the design parameters: $b_{c}, t_{t}, h_{d}, t_{d}, f_{y d}$, and $f_{y t}$.

2) Determine the width factors, $\alpha_{d}$ and $\alpha_{t}$. For more accurate results, the second approach (Fig. 12(b)) is more highly recommended.

3) Calculate the diaphragm design capacity, $T_{\text {diaph }}$, using Eq. (3).

By way of illustration, the design procedure can be applied to the same configuration as in the calculation examples $\left(b_{c}=\right.$ $600 \mathrm{~mm}, t_{t}=16 \mathrm{~mm}, h_{d}=80 \mathrm{~mm}, t_{d}=20 \mathrm{~mm}, f_{y d}=f_{y t}=300$ $\mathrm{MPa})$. By using the second approach, the width factors, $\alpha_{d}$ and $\alpha_{t}$, are 0.7 and 0.23 respectively. Therefore, the diaphragm 
axial capacity, $T_{\text {diaph }}$, is $1608.8 \mathrm{kN}$, which is $22 \%$ lower than the value obtained from the finite element analysis.

\section{CONCLUSIONS}

1) Three design methods are considered to calculate the axial capacity of external diaphragm plates connected to square CFST columns: the CIDECT method; the equivalent beam method; and the tie method. Among the methods, only the equivalent beam method considers the effect of bidirectional loading.

2) Finite element analysis results show that perpendicular diaphragm forces do not affect the external diaphragm axial capacity. This finding is consistent with the CIDECT method and the tie method. However, the CIDECT method has a limited range of validity and gives non-conservative design capacity predictions. The tie method is the most promising design method due to its assumption on the perpendicular load interaction and the conservativeness.

3) A formulation which considers the contribution of the steel tube and the diaphragm plate is proposed for modifying the tie method. In the evaluated range of configuration, the modified tie method can accurately predict a lower bound estimate of the capacity of an external diaphragm connection.

\section{ACKNOWLEDGEMENTS}

The authors are grateful to the University of Canterbury for its support in providing the ABAQUS license. The authors also wish to thank Mr. Dave Anderson from John Jones Steel Ltd. Christchurch for sharing his knowledge of construction practices.

\section{REFERENCES}

1. Morino S, Uchikoshi $M$ and Yamaguchi I (2001). "Concrete-filled steel tube column system - its advantages". Steel Structures, 1: 33-44.

2. Morino S and Tsuda K (2003). "Design and construction of concrete-filled steel tube column system in Japan". Earthquake Engineering and Engineering Seismology, 4(1): $51-73$

3. Alostaz YM and Schneider SP (1996). "Analytical behavior of connections to concrete-filled steel tubes." Journal of Constructional Steel Research, 40(2): 95-127.

4. Schneider SP and Alostaz YM (1998). "Experimental behavior of connections to concrete-filled steel tubes". Journal of Constructional Steel Research, 45(3): 321-352.

5. Wu LY, Chung LL, Tsai SF, Lu CF and Huang GL (2007). "Seismic behavior of bidirectional bolted connections for CFT columns and H-beams". Engineering Structures, 29: 395-407.

6. Li X, Xiao Y and Wu YT (2009). "Seismic behavior of exterior connections with steel beams bolted to CFT columns". Journal of Constructional Steel Research, 65 : 1438-1446.
7. Sheet IS, Gunasekaran U and MacRae GA (2013). "Experimental investigation of CFT column to steel beam connections under cyclic loading". Journal of Constructional Steel Research, 86: 167-182.

8. Wang JF, Han LH and Uy B (2009). "Behaviour of flush end plate joints to concrete-filled steel tubular columns". Journal of Constructional Steel Research, 65: 925-939.

9. Yao H, Goldsworthy H and Gad E (2008). "Experimental and Numerical Investigation of the Tensile Behavior of Blind-Bolted T-Stub Connections to Concrete-Filled Circular Columns". Journal of Structural Engineering, 134: 198-208.

10. Kang CH, Shin KJ, Oh YS and Moon TS (2001). "Hysteresis behavior of CFT column to H-beam connections with external T-stiffeners and penetrated elements”. Engineering Structures, 23: 1194-1201.

11. Shin KJ, Kim YJ, Oh YS and Moon TS (2004). "Behavior of welded CFT column to H-beam connections with external stiffeners". Engineering Structures, 26: 18771887.

12. Shin KJ, Kim YJ and Oh YS (2008). "Seismic behaviour of composite concrete-filled tube column-to-beam moment connections". Journal of Constructional Steel Research, 64: 118-127.

13. Park JW, Kang SM and Yang SC (2005). "Experimental Studies of Wide Flange Beam to Square Concrete-Filled Tube Column Joints with Stiffening Plates around the Column". Journal of Structural Engineering, 131(12): 1866-1876.

14. Kang L, Leon RT and Lu X (2015). "Shear strength analyses of internal diaphragm connections to CFT columns." Steel and Composite Structures, 18(5): 10831101.

15. Nie J, Qin K and Cai CS (2008). "Seismic behavior of connections composed of CFSSTCs and steel-concrete composite beams-experimental study". Journal of Constructional Steel Research, 64: 1178-1191.

16. Chunhaviriyakul P, MacRae GA, Anderson D, Clifton GC and Leon RT (2015). "Suitability of CFT columns for New Zealand Moment Frames". Bulletin of the New Zealand Society for Earthquake Engineering, 48(1): 63-79.

17. Kurobane Y, Packer JA, Wardenier J and Yeomans N (2004). "Design Guide for Structural Hollow Section Column Connections". TÜV-Verlag GmbH, Koln, Germany, ISBN 3-8249-0802-6, 215 pp.

18. MacRae GA (2013). "Steel Research Panel Idea Registration Form: External diaphragm design". IR GAM8, HERA, Auckland, NZ.

19. SIMULIA (2012). "Abaqus/CAE User's Manual”. Dassault Systèmes, USA, 1137 pp.

20. Standards Australia (1998). "AS 4100-1998: Steel Structures". Standards Australia, NSW, Australia, 198 pp.

21. Standards New Zealand (1997). "NZS 3404: Part 1 Steel Structures Standard". Standards New Zealand, Wellington, $\mathrm{NZ}, 283 \mathrm{pp}$ 